\title{
Clarithromycin in the treatment of RSV bronchiolitis: a double-blind, randomised, placebo-controlled trial
}

\author{
F. Tahan*, A. Ozcan\# and N. Koc ${ }^{*}$
}

ABSTRACT: Respiratory syncytial virus (RSV) bronchiolitis is the most common lower respiratory tract infection in infancy. To date, there is no effective therapy for RSV bronchiolitis.

In order to investigate the efficacy of clarithromycin in the treatment of RSV bronchiolitis, the present authors conducted a randomised, double-blind, placebo-controlled trial comparing clarithromycin with placebo in 21 infants with a diagnosis of RSV bronchiolitis. The infants were randomised to receive clarithromycin or placebo daily for 3 weeks. Levels of interleukin (IL)-4, IL8, eotaxin, and interferon- $\gamma$ were determined in plasma, before and after treatment, using ELISA. Six months after treatment, parents were surveyed as to whether their child had experienced wheezing within the previous 6 months.

Treatment with clarithromycin was associated with a statistically significant reduction in the length of hospital stay, the duration of need for supplemental oxygen and the need for $\beta_{2}$-agonist treatment. There were significant decreases in plasma IL-4, IL-8 and eotaxin levels after 3 weeks of treatment with clarithromycin. Readmission to the hospital within 6 months after discharge was significantly lower in the clarithromycin group.

In conclusion, clarithromycin has statistically significant effects on the clinical and laboratory findings in respiratory syncytial virus bronchiolitis. Therefore, clarithromycin treatment may be helpful in reducing the short-term effects of respiratory syncytial virus bronchiolitis.

KEYWORDS: Bronchiolitis, clarithromycin, eotaxin, interleukin-4, interleukin-8, respiratory syncytial virus

$\mathbf{R}$ espiratory syncytial virus (RSV) bronchiolitis is the most common lower respiratory tract infection in infancy, occurring in $90 \%$ of children of $<2$ yrs of age [1, 2]. Severe RSV infection in the first 6 months of life is often followed by recurrent childhood wheezing [3].

Airway inflammation in RSV bronchiolitis is a multicellular process involving epithelial cells, eosinophils and neutrophils. Epithelial cells have always been thought of as major contributors to the inflammatory process of the airways during RSV infection. RSV causes widespread damage to bronchial epithelium and stimulates epithelial cells to secrete a wide range of pro-inflammatory cytokines and chemokines [4]. The increase in virus-induced chemokines recruits leukocytes to the airway and could increase binding of neutrophils and eosinophils to epithelial cells.

Interleukin (IL)-8 is a key chemokine produced by RSV-infected airway cells and is involved in the activation and recruitment of neutrophils [5].
Neutrophils play a major role in the pathophysiology of RSV bronchiolitis [6].

RSV infection can enhance the influx of eosinophils into the lungs [7]. KRISTJANSSON et al. [8] promotes infiltration and activation of eosinophils. In vitro studies [9-12] have indicated that RSV infection results in the release of high concentrations of regulated on activation, normal T-cell expressed and secreted (RANTES) and macrophage inflammatory protein $-1 \alpha$.

RSV infection may influence the development of asthma by enhancing allergic sensitisation in the developing lung. The normal respiratory tract has evolved in close contact with aeroallergens. Sensitisation to aeroallergens is unlikely to occur through an intact mucosal epithelium. Disturbance of the respiratory mucosal surface during viral infection may allow allergens to gain access to the subepithelial layer and interact with antigen-presenting cells and inflammatory cells, leading to allergic sensitisation [13]. showed that RSV infection during early infancy

\section{AFFILIATIONS}

*Depts of Paediatric Allergy,

\#Paediatrics, and

"Microbiology, Erciyes University

School of Medicine, Kayseri, Turkey.

CORRESPONDENCE

F. Tahan

Dept of Paediatric Allergy

Erciyes University School of

Medicine

Kayseri 38039

Turkey

Fax: 903524375825

E-mail: tahanfulya@yahoo.com

Received:

February 272006

Accepted after revision:

August 292006 
In order to break the apparent link that exists between RSV bronchiolitis and childhood asthma, an effective therapy against its short-term effects is necessary.

The treatment of infants with bronchiolitis has been largely supportive, with supplemental oxygen, minimal handling of the infant and the use of intravenous fluids and ventilatory support where necessary [14]. The role of bronchodilators is controversial [14]. The American Academy of Paediatrics does not recommend using corticosteroids for the treatment of RSV symptoms. Despite many attempts to find effective treatments for patients with RSV bronchiolitis, no consistently effective therapy has yet been described.

Macrolides are widely used in the treatment of infectious diseases, including respiratory infections [15]. There is increasing evidence of an anti-inflammatory effect of macrolides.

Clarithromycin, one of the newer macrolides, has been shown to have immunomodulatory effects. Possible mechanisms of the anti-inflammatory effects of clarithromycin include inhibition of neutrophil migration and pro-inflammatory cytokines, increase in phagocytosis and natural killer cell activity and induction of eosinophil apoptosis [16-20]. Clarithromycin suppresses the production of pro-inflammatory cytokines via inhibition of nuclear factor- $\kappa \mathrm{B}$ activation [21].

As RSV infection initiates an immune inflammatory response that may produce long-lasting harmful effects, it was hypothesised that the course of the disease could be modified and wheezing after bronchiolitis prevented by administering macrolides to infants during an acute episode of RSV bronchiolitis. To investigate this, the present authors studied the use of 3 weeks of macrolide therapy in the treatment of RSV bronchiolitis in a double-blind, randomised, placebocontrolled trial. The current authors measured the levels of the eosinophilic CC chemokine eotaxin (thought to have a role in eosinophilic inflammation) and the CXC chemokine IL-8 (thought to have a central role in neutrophilic inflammation). With the knowledge that severe RSV infections during early infancy are associated with the excessive production of $\mathrm{T}$ helper cell (Th) type 2 cytokines [22, 23], the present authors measured the levels of Th2 cytokine IL-4 (thought to have a central role in Th2-mediated diseases) and the Th1 cytokine interferon (IFN) $-\gamma$.

The present authors hypothesised that a 3-week course of clarithromycin therapy would result in a reduction in the hospital length of stay (LOS), a reduction in plasma IL-4, IL-8 and eotaxin levels and an enhanced production of IFN- $\gamma$.

\section{MATERIAL AND METHODS Patients}

In the RSV season of January to April 2005, 30 infants $\leqslant 7$ months of age with documented respiratory tract infection with RSV admitted to the Dept of Paediatrics at the Erciyes University Hospital in Kayseri, Turkey, were enrolled in the present study. Infants with a first episode of wheezing requiring hospitalisation and with a clinical diagnosis of bronchiolitis were considered for entry into the study. Bronchiolitis was diagnosed based on clinical findings, including wheezing or wheezing with crackles, and respiratory distress with retractions. Infants with cardiac disease, cystic fibrosis or chronic neonatal lung disease associated with prematurity were excluded. Infants were also excluded if they had received corticosteroids within $24 \mathrm{~h}$ before presentation or bronchodilators within $4 \mathrm{~h}$ before presentation. The present study was approved by the Erciyes University Hospital ethics committee. Written informed consent was obtained from the parents before enrolment.

\section{Bronchiolitis diagnosis and treatment}

All children admitted to hospital with bronchiolitis were treated according to the same clinical pathway to minimise the variability of the results. A nasopharyngeal aspiration sample (NPA) was obtained routinely from all patients for detection of RSV. RSV infection was diagnosed by direct immunofluorescent staining of the NPA. An infant was considered ready for discharge when he/she had not received supplemental oxygen for $10 \mathrm{~h}$, had minimal or no chest retractions and was feeding adequately without the need for intravenous fluids. Supplemental oxygen was administered to those cases showing oxygen saturation $\left(\mathrm{Sp}_{\mathrm{p}} \mathrm{O}_{2}\right)$ levels $<94 \%$, as determined by pulse oximetry (Trusat pulse oximeter; Datex-Ohmeda, Louisville, CO, USA). Supplemental oxygen was discontinued when $\mathrm{Sp}, \mathrm{O}_{2}$ was consistently $>93 \%$ or when the infant's condition had been stable for $4 \mathrm{~h}$ and he/she was starting to tolerate oral feeding.

Intravenous fluids were administered when supplemental oxygen was required, the respiratory rate was $>60$ breaths $\cdot \mathrm{min}^{-1}$ or oral intake was inadequate. When the infant was able to tolerate oral feeding, the use of intravenous fluids was stopped.

The infants received $\beta_{2}$-agonist treatment based on oxygen saturation, respiratory rate and respiratory effort. In particular, the infants received $\beta_{2}$-agonist treatment when oxygen saturation was $<94 \%$, the respiratory rate was $>60$ breaths $\cdot \mathrm{min}^{-1}$, there was the presence of wheezing on auscultation of the chest or respiratory distress with retractions.

\section{Randomisation and investigational therapy}

After written informed parental consent had been obtained and the NPA had been found to be positive for RSV, the infants were randomised by a single study nurse to receive clarithromycin $\left(15 \mathrm{mg} \cdot \mathrm{kg}^{-1}\right)$ or placebo daily for 3 weeks. Simple randomisation was used [24]. Patients, parents and investigators were kept blinded to the randomisation until completion of the study. The primary outcome was LOS. Secondary outcomes included changes in the IL-4, IL-8, eotaxin and IFN- $\gamma$ levels, readmission rate and wheezing after discharge.

Each infant was assigned one bottle of solution containing either clarithromycin (clarithromycin, silicon dioxide, saccharose, kxantan zamk, tutti frutti aroma, potassium sorbate, citric acid, titanium dioxide, maltodextrin and water) or placebo (silicon dioxide, saccharose, kxantan zamk, tutti frutti aroma, potassium sorbate, citric acid, titanium dioxide, maltodextrin and water).

\section{Clinical data}

Detailed clinical histories, including the duration of symptoms before presentation at the hospital, the medical history, the infant's ability to feed, previous medication, parental smoking 
history and family history of atopy were recorded. Observations at admission included respiratory and heart rate while the infant was quiet, temperature, respiratory effort, $\mathrm{Sp}, \mathrm{O}_{2}$ while breathing room air, presence of wheezing or crackles on auscultation of the chest, and level of hydration. Each infant's condition was classified as mild, moderate or severe according to a severity score [14] calculated from the $\mathrm{Sp}_{\mathrm{p}} \mathrm{O}_{2}$, respiratory rate and respiratory effort observed at admission (table 1). Six months following completion of clarithromycin or placebo therapy, parents were asked whether their child had experienced wheezing during the previous 6 months.

\section{Laboratory studies}

RSV was detected by direct immunofluorescent staining of NAP (Monofluo screen RSV; Bio-Rad, Marnes-la-Coquette, France).

Peripheral blood $(5 \mathrm{~mL})$ was obtained from all the children pre-treatment and after 3 weeks of macrolide or placebo treatment. The samples were centrifuged at 2,000 rpm for $30 \mathrm{~min}$ and the serum was frozen at $-20^{\circ} \mathrm{C}$ for storage prior to ELISA assay. The serum samples were analysed, both during the acute phase of the disease and after 3 weeks of treatment, for levels of IL-4, IL-8, eotaxin and IFN- $\gamma$.

Total immunoglobulin (Ig)E and eosinophil counts were obtained. Skin testing was performed with a battery of 25 antigens with appropriate histamine positive and saline/ diluent negative controls on the upper back of the children at

\section{TABLE 1 Demographic characteristics of the infants}

\begin{tabular}{|c|c|c|c|}
\hline Characteristic & Clarithromycin & Placebo & p-value \\
\hline Subjects $n$ & 12 & 9 & \\
\hline Age months & $2(1-6)$ & $2(1-7)$ & $>0.05^{\#}$ \\
\hline Sex male & $8(66)$ & $4(45)$ & $>0.05^{\circ}$ \\
\hline Parental smoking & $4(33)$ & $3(33)$ & $>0.05^{\circ}$ \\
\hline \multicolumn{4}{|l|}{$\begin{array}{l}\text { Duration of wheezing at } \\
\text { admission }\end{array}$} \\
\hline No wheezing & 0 & 0 & \\
\hline$<3$ days & $8(66)$ & $6(66)$ & $>0.05^{\circ}$ \\
\hline 3-6 days & $4(34)$ & $3(34)$ & \\
\hline$>6$ days & 0 & 0 & \\
\hline \multicolumn{4}{|l|}{ Severity of disease } \\
\hline Mild & $2(16)$ & 2 (22) & \\
\hline Moderate & $9(72)$ & $6(66)$ & \\
\hline Severe & $1(12)$ & $1(11)$ & $>0.05^{\circ}$ \\
\hline \multicolumn{4}{|l|}{ Supplemental oxygen } \\
\hline No oxygen & $2(16)$ & 2 (22) & $>0.05^{\circ}$ \\
\hline Oxygen & $10(84)$ & $7(78)$ & \\
\hline Skin test positivity \% & 0 & 0 & $>0.05^{\circ}$ \\
\hline Eosinophil count & $185(20-544)$ & $150(30-250)$ & $>0.05^{\#}$ \\
\hline $\operatorname{lgE~ku} \cdot \mathrm{L}^{-1}$ & $12.5(1-94)$ & $15(1-30)$ & $>0.05^{\#}$ \\
\hline Family history of atopy & 0 & 0 & $>0.05^{\circ}$ \\
\hline
\end{tabular}

Data are presented as median (interquartile range) and $n(\%)$, unless otherwise stated. IgE: immunoglobulin E. ${ }^{\#}$ : Mann-Whitney U-test; " ${ }^{\circ}$ Chi-squared test. presentation. Reactions with an induration $>3 \mathrm{~mm}$ of that of the negative control were considered positive.

IgE levels were measured with Uni-Cap technology in accordance with the specifications of the manufacturer (Pharmacia, Kalamazoo, MI, USA). Eosinophil counts were determined from Coulter Counter (Automated Haematology Analyser, XT-2000; Sysmex, Kobe, Japan) leukocyte measurements.

\section{Chemokine measurements}

The ELISA kits used to detect IL-4, IL-8, eotaxin and IFN- $\gamma$ levels were obtained from Biosource (Camarillo, CA, USA). Their sensitivity was $2 \mathrm{pg} \cdot \mathrm{mL}^{-1}, 5 \mathrm{pg} \cdot \mathrm{mL}^{-1}, 2.2 \mathrm{pg} \cdot \mathrm{mL}^{-1}$ and $4 \mathrm{pg} \cdot \mathrm{mL}^{-1}$, respectively.

\section{Statistical analyses}

Chemokine levels in the plasma were compared according to Mann-Whitney U-tests or Wilcoxon tests, depending upon the distribution of the data. Sex, parental smoking, readmission to the hospital, duration of wheezing at admission, severity of the disease, requiring supplemental oxygen, skin test positivity and family history of atopy were compared according to Chisquared tests. A p-value $<0.05$ was considered significant.

\section{RESULTS}

A total of 30 infants were assigned to treatment: 15 to clarithromycin and 15 to placebo. During the study period, nine patients (three in the clarithromycin group and six in the placebo group) were excluded from the study due to the fact that they received steroid treatment during hospitalisation. There were no significant differences between the groups at randomisation in terms of demographic variables. There were no significant differences between the groups at admission in terms of the duration of wheezing and the severity of the disease (table 1). Likewise, there were no significant differences between the groups with respect to the number of eosinophils and plasma IgE levels ( $p>0.05$, Mann-Whitney Utest; table 1).

\section{Primary end-points}

Treatment with clarithromycin was associated with a significant reduction in LOS (51 h versus $88 \mathrm{~h}(\mathrm{p}<0.05)$; table 2$)$. The duration of need for supplemental oxygen and intravenous fluids was higher in the placebo group $(31$ versus $72 \mathrm{~h}(\mathrm{p}<0.05)$ and 26 versus $56 \mathrm{~h}(\mathrm{p}<0.05)$, respectively; Mann-Whitney Utest; table 2).

There was a significant difference in the use of $\beta_{2}$-agonist treatment between the clarithromycin and placebo groups. Among infants receiving $\beta_{2}$-agonist treatment, those in the placebo group received it for a longer period than those in the clarithromycin group (5 days versus 7 days $(\mathrm{p}<0.05)$, MannWhitney U-test; table 2).

\section{Secondary end-points}

Comparison of pre-treatment plasma chemokine levels revealed that there was no significant difference between the clarithromycin and placebo groups ( $p>0.05$, Mann-Whitney U-test). 


\begin{tabular}{|c|c|c|c|}
\hline Variable & Clarithromycin & Placebo & p-value \\
\hline LOS h & $51(48-68)$ & $88(72-100)$ & $<0.05^{\#}$ \\
\hline Duration of supplemental oxygen need $h$ & $31(28-42)$ & $72(52-80)$ & $<0.05^{\#}$ \\
\hline Duration of supplemental intravenous fluid $h$ & $26(22-36)$ & $56(46-66)$ & $<0.05^{\#}$ \\
\hline Readmission to hospital & $1(8.3)$ & $4(44.4)$ & $<0.05^{+}$ \\
\hline
\end{tabular}

Data are presented as median (interquartile range) and $\mathrm{n}(\%)$, unless otherwise stated. LOS: length of stay. ${ }^{\#}$ : Mann-Whitney U-test; ${ }^{\circ}$ : within 6 months of discharge; ${ }^{+}$ Chi-squared test.

Three weeks of clarithromycin therapy was associated with significant changes in the plasma chemokine levels. There were significant decreases in the plasma IL-4, IL-8 and eotaxin levels following clarithromycin therapy $(p<0.05$, Wilcoxon; figs $1 \mathrm{a}, \mathrm{b}$ and $\mathrm{c}$ ). No differences in plasma eotaxin, IL-4 and IL8 levels were observed for infants receiving placebo treatment ( $p>0.05$, Wilcoxon; figs $1 \mathrm{a}, \mathrm{b}$ and $\mathrm{c}$ ). IFN- $\gamma$ levels were below the limit of detection in all infants.

Five patients were readmitted to the hospital with wheezing within 6 months of discharge: four $(44 \%)$ from the placebo group and one $(8.3 \%)$ from the clarithromycin group $(\mathrm{p}<0.05$, Chi-squared test; table 2). The parents of those infants that were not readmitted to the hospital were surveyed on the phone regarding wheezing during the first 6 months posttreatment. None reported wheezing during that time.

\section{DISCUSSION}

To the best of the present authors' knowledge, this is the first study to investigate the effect of clarithromycin treatment in RSV bronchiolitis. The present study was designed to determine whether clarithromycin treatment had any clinical and/or laboratory effect on clinical and/or biomarker outcomes in RSV bronchiolitis. In order to explore a potential immunomodulatory effect of clarithromycin, plasma levels of IL-4, IL-8, eotaxin and IFN- $\gamma$ were measured. It has been shown that clarithromycin, when compared with placebo, is capable of significant changes in some of these parameters.

In RSV bronchiolitis, treatment with clarithromycin had a statistically significant effect on LOS, use of $\beta_{2}$-agonist treatment and plasma IL-4, IL-8 and eotaxin levels.

Clarithromycin is widely used in the treatment of infectious diseases and has an antibacterial effect. The question is whether the clinical improvement is related to its antibacterial effect. It is known that acute bronchiolitis is predominantly a viral disease. RSV is responsible for $>50 \%$ of cases [25]. Other agents include parainfluenza, adenovirus and, occasionally, other viruses. There is no evidence of a bacterial cause for bronchiolitis [25]. In the present study group, bacterial infection was not investigated due to all subjects testing RSV positive, their leukocyte counts being normal and their Creactive protein levels negative.

How could clarithromycin act in the short-term to effect changes in LOS and the use of $\beta_{2}$-agonist treatment in bronchiolitis? The present authors considered that suppressive effects of clarithromycin on the plasma IL-4, IL-8 and eotaxin levels may have a role in suppression of airway hyperresponsiveness or may inhibit cholinergic neuroeffector transmission in human airway smooth muscle, thereby influencing bronchial tone.

RSV is suspected to potentially cause increased airway responsiveness by enhancing parasympathetic bronchoconstrictive responses [26]. The existing documentation reporting that macrolides attenuate the contractile response of human isolated bronchial strips to electrical field stimulation [18] leads to the hypothesis that macrolides might influence bronchial tone by inhibiting cholinergic neuroeffector transmission in human airway smooth muscle.

Airway hyperresponsiveness appears to be one manifestation of the airway inflammation induced by RSV. It has been shown that a correlation exists between numbers of mast cells, eosinophils and neutrophils and the degree of airway hyperresponsiveness [27]. It has been further shown that enhanced IL-4, IL-8 and eotaxin levels have a role in the development of airway inflammation and hyperresponsiveness [28-30]. PITREZ et al. [31] suggested that there were significant correlations between IL-4 levels in blood and airway secretions. The present authors found significant decreases in plasma IL-4 levels after 3 weeks of clarithromycin therapy. IL- 4 is a critical cytokine in the mediation of allergic airway inflammation. IL-4 is critical in the switching of Bcellsto IgE production. It also promotes mucus hypersecretion and ascular cell adhesion molecule- 1 expression in endothelial cells, resulting in the recruitment of eosinophils [32].

It is known that enhanced IL-4 has a critical role in the development of airway hyperresponsiveness [28]. Inhalation of IL-4 causes the development of sputum eosinophilia and increased airway hyperreactivity [33]. It is hypothesised that clarithromycin, by decreasing plasma IL-4 levels, may reduce the need for $\beta_{2}$-agonist therapy in RSV bronchiolitis. Indeed, infants in the placebo group required significantly longer duration of $\beta_{2}$-agonist therapy than infants in the clarithromycin group.

Neutrophil-mediated inflammation is involved in the augmentation of bronchial reactivity in RSV bronchiolitis [26, 29, $34,35]$. IL- 8 and leukotriene (LT) $B_{4}$ are known neutrophil chemotactic factors and play an important role in neutrophilic 

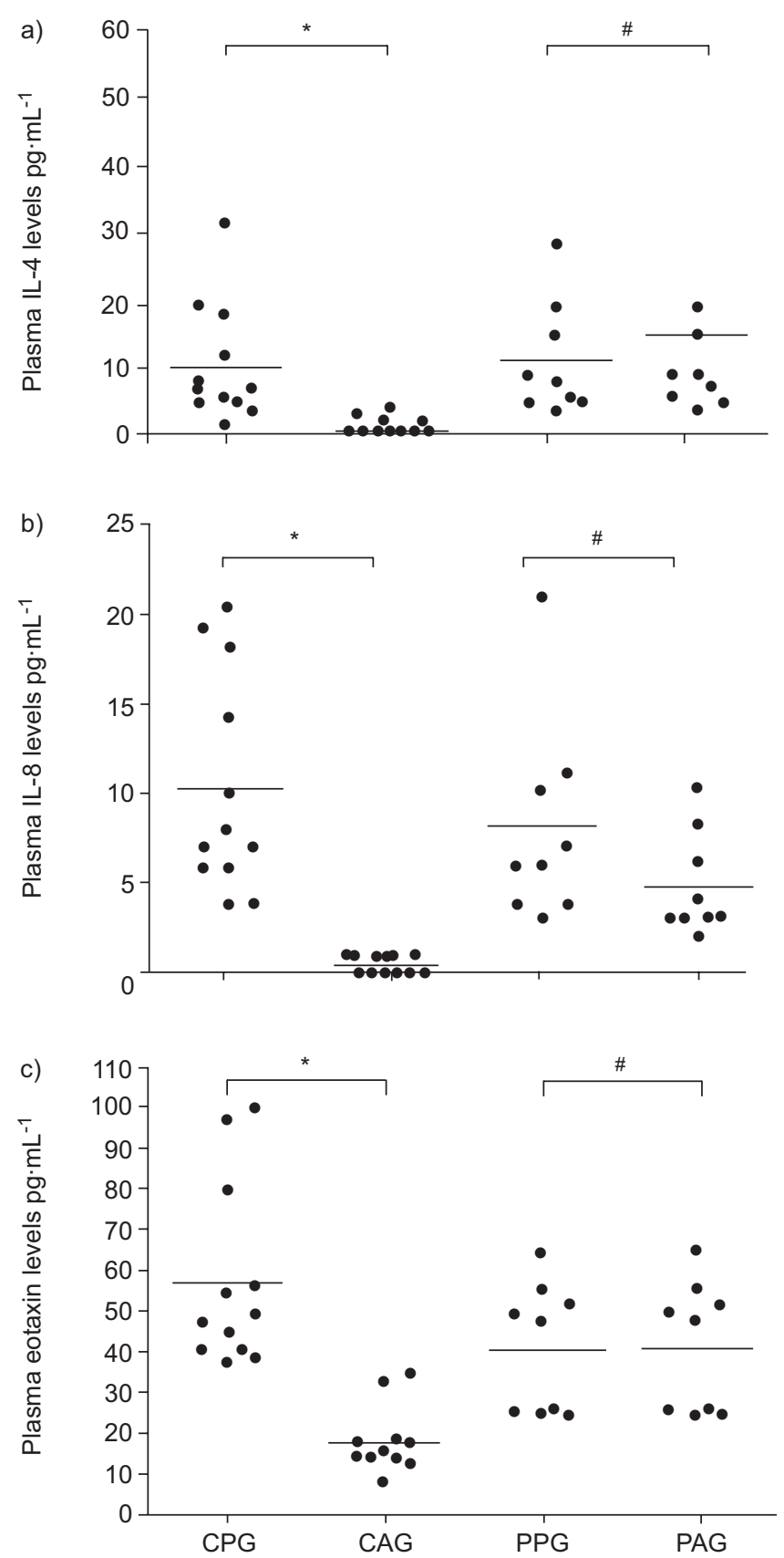

FIGURE 1. Plasma interleukin (IL)-4 (a), IL-8 (b) and eotaxin levels (c). CPG: clarithromycin pre-treatment group; CAG: clarithromycin after treatment group PPG: placebo pre-treatment group; PAG: placebo after treatment group. *: $p<0.05$; \#: $p>0.05$.

airway inflammation [36]. Previous studies [36, 37] demonstrated that one of the anti-inflammatory mechanisms of macrolides relates to the inhibition of IL-8 production. Macrolides also inhibit formation of $\mathrm{LTB}_{4}$ and neutrophil infiltration into lung tissue and reduce the formation of superoxide by neutrophils [38-42]. Steroids fail to downregulate RSV-induced IL-8 secretion in infants. This may explain why steroid therapy is unsuccessful in RSV bronchiolitis [43].
The present authors found significant decreases in plasma eotaxin levels following clarithromycin therapy. Eotaxin is highly specific for eosinophil recruitment [30]. Macrolides attenuate the release of eotaxin, granulocyte-macrophage colony-stimulating factor and RANTES [30]. Lung fibroblasts are an important source of eosinophil chemotactic activity. Inhibitory effects of erythromycin on eosinophil chemotactic cytokine release by lung fibroblasts may be one of the mechanisms of decreased airway hyperresponsiveness and the resulting amelioration of disease activity following therapy with that agent [30]. Macrolides may also protect epithelial cells at inflamed sites by inhibiting the release of reactive oxygen species from eosinophils [44]

Severe RSV infections during early infancy are associated with the excessive production of Th2 cytokines [22, 23], which has been suggessted as a risk factor for the development of asthma and allergic sensitisation [45]. Macrolides may normalise the Th1/Th2 lymphocyte balance [38]. They regulate immunologic activities by enhancing production of IFN- $\gamma$ and by reducing production of IL-4 and IL-5 [46]. Treatment that restores the Th1/Th2 cytokine balance to the relative type 1 predominance may ameliorate short- and long-term effects of RSV disease.

The present authors have no data concerning the long-term effects of clarithromycin in RSV bronchiolitis. Further investigations will be required to understand the long-term effects of clarithromycin, especially reducing recurrent wheezing, allergic sensitisation and asthma.

Numerous studies $[47,48]$ have shown that $75 \%$ of patients with RSV bronchiolitis exhibit recurrent wheezing or pulmonary function abnormalities years later. As discussed previously, RSV infection may enhance allergic sensitisation in the developing lung through disruption of the respiratory epithelium. Macrolides promote the reparative process in the chronically inflamed upper and lower respiratory tract and are associated with salutary tissue reparative effects in patients with chronic inflammatory sinopulmonary diseases, such as chronic sinusitis, asthma, bronchiectasis, cystic fibrosis and diffuse panbronchiolitis [49]. Suppressing IgE [49] and the tissue reparative effects of macrolides may partly protect against allergic sensitisation.

Further investigations of larger groups of children will be required to elucidate potential effects of macrolides in this area.

In conclusion, treatment with clarithromycin in respiratory syncytial virus bronchiolitis had statistically significant effects on hospital length of stay, duration of need for supplemental oxygen and rate of readmission to the hospital within 6 months after discharge. Suppressive effects of clarithromycin on the plasma interleukin- 4 , interleukin- 8 and eotaxin levels may have a role in suppression of airway hyperresponsiveness and epithelial cell damage, leading to a reduction in postbronchiolitic symptoms and allergic sensitisation. Effective therapy against the short-term effects of respiratory syncytial virus bronchiolitis could be important in reducing subsequent morbidity. The present study should encourage further studies to confirm the use of clarithromycin in respiratory syncytial virus bronchiolitis, especially in infants of $<6$ months of age. 


\section{REFERENCES}

1 Phelan P, Olinsky A, Robertson C. Clinical Patterns of Acute Respiratory Infections. Oxford, Blackwell Science, 1994; pp. 52-93.

2 Glezen P, Denny FW. Epidemiology of acute lower respiratory disease in children. $N$ Engl J Med 1973; 288: 498-505.

3 Martinez FD, Wright AL, Taussing LM, Holberg CJ, Halonen M, Morgan WJ. Asthma and wheezing in the first six years of life. The Group Health Medical Associates. N Engl J Med 1995; 332: 133-138.

4 Folkerts G, Busse WW, Nijkamp FP, Sorkness R, Gern JE. Virus-induced airway hyperresponsiveness and asthma. Am J Respir Crit Care Med 1998; 157: 1708-1720.

5 Bataki EL, Evans GS, Everard ML. Respiratory syncytial virus and neutrophil activation. Clin Exp Immunol 2005; 140: 470-477.

6 Yasui K, Baba A, Iwasaki Y, et al. Neutrophil-mediated inflammation in respiratory syncytial viral bronchiolitis. Pediatr Int 2005; 47: 190-195.

7 Schwarze J, Hamelmann E, Bradley KL, Takeda K, Gelfand EW. Respiratory syncytial virus infection results in airway hyperresponsiveness and enhanced airway sensitization to allergen. J Clin Invest 1997; 100: 226-233.

8 Kristjansson S, Bjarnarson SP, Wennergren G, et al. Respiratory syncytial virus and other respiratory viruses during the first 3 months of life promote a local Th2-like response. J Allergy Clin Immunol 2005; 116: 805-811.

9 Becker S, Quay J, Soukup J. Cytokine (tumor necrosis factor, IL-6 and IL-8) production by respiratory syncytial virus-infected human alveolar macrophages. I Immunol 1991; 147: 4307-4312.

10 Noah TL, Becker S. Respiratory syncytial virus-induced cytokine production by a human bronchial epithelial cell line. Am J Physiol 1993; 265: 472-478.

11 Arnold R, Humbert B, Werchau H, Gallati H, Konig W. Interleukin-8, interleukin-6, and soluble tumor necrosis receptor type I release from a human pulmonary epithelial cell line (A549) exposed to respiratory syncytial virus. Immunol 1994; 82: 126-133.

12 Olszewska-Pazdrak B, Casola A, Saito T, et al. Cell-specific expression of RANTES, MCP-1, and MIP-alpha (by lower airway epithelial cells and eosinophils infected with respiratory syncytial virus. J Virol 1998; 72: 4756-4764.

13 Mallia P, Johnston SL. Respiratory viruses: do they protect from or induce asthma? Allergy 2002; 57: 1118-1129.

14 Wainwright C, Altamirano L, Cheney M, et al. A multicenter, randomized, double-blind, controlled trial of nebulized epinephrine in infants with acute bronchiolitis. $N$ Engl J Med 2003; 349: 27-35.

15 Ferrara G, Losi M, Franco F, Corbetta L, Fabbri LM, Richeldi L. Macrolides in the treatment of asthma and cystic fibrosis. Respir Med 2005; 99: 1-10.

16 Ianaro A, Ialenti A, Maffia P, et al. Anti-inflammatory activity of macrolide antibiotics. J Pharmacol Exp Ther 2000; 292: 156-163.

17 Anderson R, Theron AJ, Feldman C. Membrane-stabilizing, anti-inflammatory interactions of macrolides with human neutrophils. Inflammation 1996; 20: 693-705.

18 Labro MT. Anti-inflammatory activity of macrolides: a new therapeutic potential? J Antimicrob Chemother 1998; 41: $37-46$.
19 Morikawa K, Watabe $\mathrm{H}$, Araake M, Morikawa S. Modulatory effect of antibiotics on cytokine production by human monocytes in vitro. Antimicrob Agents Chemother 1996; 40: 1366-1370.

20 Adachi T, Motojima S, Hirata A, et al. Eosinophil apoptosis caused by theophylline, glucocorticoids and macrolides after stimulation with IL-5. J Allergy Clin Immunol 1996; 98: 207-215.

21 Ichiyama $\mathrm{T}$, Nishikawa $\mathrm{M}$, Yoshitomi $\mathrm{T}$, et al. Clarithromycin inhibits NF-KappaB activation in human peripheral blood mononuclear cells and pulmonary epithelial cells. Antimicrob Agents Chemother 2001; 45: 44-47.

22 Roman M, Calhoun WJ, Hinton KL, et al. Respiratory syncytial virus infection in infants is associated with predominant Th2-like response. Am J Respir Crit Care Med 1997; 156: 190-195.

23 Kristjansson S, Bjarnarson SP, Wennergren G, et al. Respiratory syncytial virus and other respiratory viruses during the first 3 months of life promote a local Th2-like response. J Allergy Clin Immunol 2005; 116: 805-811.

24 Beller EM, Gebski V, Keech AC. Randomisation in clinical trials. Med J Aust 2002; 177: 565-567.

25 Goodman D. Inflammatory disorders of the small airways. In: Behrman RE, Kliegman RM, Jenson HB, eds. Textbook of Paediatrics. 17th Edn. Philadelphia, Saunders, 2003; pp. 1414-1416.

26 Everard ML, Swarbrick A, Wrightham M, et al. Analysis of cells obtained by bronchial lavage of infants with respiratory syncytial virus infection. Arch Dis Child 1994; 71: 428-432.

27 O'Byrne PM. Mechanisms of airway hyperresponsiveness. In: Holgate ST, Busse WW, eds. Inflammatory mechanisms in asthma. New York, Marcel Dekker, Inc, 1998; pp. 891-901.

28 Schwarze J, Cieslewicz G, Joetham A, et al. Critical roles for interleukin-4 and interleukin-5 during respiratory syncytial virus infection in the development of airway hyperresponsiveness after airway sensitization. Am J Respir Crit Care Med 2000; 162: 380-386.

29 Abu-Harb M, Bell F, Finn A, et al. IL-8 and neutrophil elastase levels in the respiratory tract of infants with RSV bronchiolitis. Eur Respir J 1999; 14: 139-143.

30 Sato E, Nelson DK, Koyama S, Hoyt JC, Robbins RA. Erythromycin modulates eosinophil chemotactic cytokine production by human lung fibroblasts in vitro. Antimicrob Agents Chemother 2000; 45: 401-406.

31 Pitrez PM, Ponzi D, Machado DC, Bauer ME, Jones MH, Stein RT. Discrepancy between cytokine production from peripheral blood mononuclear cells and nasal secretions among infants with acute bronchiolitis. Ann Allergy Asthma Immunol 2004; 92: 659-662.

32 Christodoulopoulos P, Tulic MK, Kontolemos M, Hamid Q. Immunopatholgy of allergic airway inflammation. In: Adkinson FN Jr, Yunginger JW, Busse WW, Bochner BS, Holgate ST, Simons FER, eds. Allergy, Principles and Practice. 6th Edn. Philadelphia, Mosby, 2003; pp. 501-514.

33 Shi HZ, Deng JM, Xu H, et al. Effect of inhaled interleukin4 on airway hyperreactivity in asthmatics. Am J Respir Crit Care Med 1998; 157: 1818-1821.

34 Faden H, Kaul TN, Ogra PL. Activation of oxidative and arachidonic acid metabolism in neutrophils by respiratory 
syncytial virus antibody complexes: possible role in disease. J Infect Dis 1983; 148: 110-116.

35 Jaovisidha P, Peeples ME, Brees AA, Carpenter LR, Moy JN. Respiratory syncytial virus stimulates neutrophil degranulation and chemokine release. J Immunol 1999; 163: 2816-2820.

36 Basyigit I, Yildiz F, Ozkara SK, Yildirim E, Boyaci H, Ilgazli A. The effect of clarithromycin on inflammatory markers in chronic obstructive pulmonary disease: preliminary data. Ann Pharmacother 2004; 38: 1400-1405.

37 Abe S, Nakamura $H$, Inoue $S$, et al. Interleukin- 8 gene repression by clarithromycin is mediated by the activator protein-1 binding site in human bronchial epithelial cells. Am J Respir Cell Mol Biol 2000; 22: 51-60.

38 Parnham MJ. Immunomodulatory effects of antimicrobials in the therapy of respiratory tract infections. Curr Opin Infect Dis 2005; 18: 125-131.

39 Tamaoki J, Kadota J, Takizawa H. Clinical implications of the immunomodulatory effects of macrolides. Am J Med 2004; 117: Suppl. 9A, 5S-11S.

40 Roche Y, Gougerot-Pocidalo MA, Fay M, Forest N, Pocidalo JJ. Macrolides and immunity: effects of erythromycin and spiramycin on human mononuclear cell proliferation. J Antimicrob Chemother 1986; 17: 195-203.

41 Labro MT, el Benna J, Babin-Chevaye C. Comparison of the in vitro effect of several macrolides on the oxidative burst of human neutrophils. J Antimicrob Chemother 1989; 24: $561-572$.
42 Konno S, Adachi M, Asano K, Okamoto K, Takahashi T. Anti-allergic activity of roxithromycin: inhibition of interleukin-5 production from mouse T lymphocytes. Life Sci 1993; 52: 25-30.

43 Thomas LH, Sharland M, Friedland JS. Steroids fail to down-regulate respiratory syncytial virus-induced IL-8 secretion in infants. Pediatr Res 2002; 52: 368-372.

44 Cui $\mathrm{CH}$, Honda $\mathrm{K}$, Saito N, et al. Effect of roxithromycin on eotaxin-primed reactive oxygen species from eosinophils. Int Arch Allergy Immunol 2001; 125: 38-41.

45 Sigurs N, Gustafsson PM, Bjarnason R, et al. Severe respiratory syncytial virus bronchiolitis in infancy and asthma and allergy at age 13. Am J Respir Crit Care Med 2005; 171: 137-141.

46 Noma T, Aoki K, Hayashi M, Yoshizawa I, Kawano Y. Effect of roxithromycin on $\mathrm{T}$ lymphocyte proliferation and cytokine production elicited by mite antigen. Int Immunopharmacol 2001; 1: 201-210.

47 Wennergren G, Kristjansson S. Relationship between respiratory syncytial virus bronchiolitis and future obstructive airway diseases. Eur Respir J 2001; 18: 1044-1058.

48 Stein RT, Sherrill D, Morgan WJ, et al. Respiratory syncytial virus in early life and risk of wheeze and allergy by age 13 years. Lancet 1999; 354: 541-545.

49 Garey KW, Alwani A, Danziger LH, Rubinstein I. Tissue reparative effects of macrolide antibiotics in chronic inflammatory sinopulmonary diseases. Chest 2003; 123: 261-265. 